\title{
On the stratigraphic integrity of leaf-wax biomarkers in loess paleosols
}

\author{
C. Häggi ${ }^{1}$, R. Zech ${ }^{1,3}$, C. McIntyre ${ }^{1}$, M. Zech ${ }^{2}$, and T. I. Eglinton ${ }^{1}$ \\ ${ }^{1}$ Geological Institute, ETH Zurich, Switzerland \\ ${ }^{2}$ Department of Soil Physics and Chair of Geomorphology, University of Bayreuth, Germany \\ ${ }^{3}$ now at: Institute of Geography, University of Bern, Bern, Switzerland
}

Correspondence to: R. Zech (godotz@gmx.de)

Received: 30 September 2013 - Published in Biogeosciences Discuss.: 29 October 2013

Revised: 3 March 2014 - Accepted: 18 March 2014 - Published: 5 May 2014

\begin{abstract}
Paleoenvironmental and paleoclimate reconstructions based on molecular proxies, such as those derived from leaf-wax biomarkers, in loess-paleosol sequences represent a promising line of investigation in Quaternary research. The main premise of such reconstructions is the synsedimentary deposition of biomarkers and dust, which has become a debated subject in recent years. This study uses two independent approaches to test the stratigraphic integrity of leafwax biomarkers: (i) long-chain $n$-alkanes and fatty acids are quantified in two sediment-depth profiles in glacial till on the Swiss Plateau, consisting of a Holocene topsoil and the underlying B and C horizons. Since glacial sediments are initially very poor in organic matter, significant amounts of leaf-wax biomarkers in the $\mathrm{B}$ and $\mathrm{C}$ horizons of those profiles would reflect postsedimentary root-derived or microbial contributions. (ii) Compound-specific radiocarbon measurements are conducted on $n$-alkanes and $n$-alkanoic (fatty) acids from several depth intervals in the loess section " $\mathrm{Cr}$ venka", Serbia, and the results are compared to independent estimates of sediment age.

We find extremely low concentrations of plant-wax $n$ alkanes and fatty acids in the $\mathrm{B}$ and $\mathrm{C}$ horizons below the topsoils in the sediment profiles. Moreover, compoundspecific radiocarbon analysis yields plant-wax ${ }^{14} \mathrm{C}$ ages that agree well with published luminescence ages and stratigraphy of the Serbian loess deposit. Both approaches confirm that postsedimentary, root-derived or microbial contributions are negligible in the two investigated systems. The good agreement between the ages of odd and even homologues also indicates that reworking and incorporation of fossil leaf waxes is not particularly relevant either.
\end{abstract}

\section{Introduction}

Biomarkers or chemical fossils are relatively poorly decomposable components of plants, microorganisms and animals, which, in some cases, record past environmental conditions (Eglinton and Eglinton, 2008). Over the last decade, biomarker analyses in loess-paleosol sequences (LPS) have become an increasingly important tool for paleoclimate reconstructions. The distributions of plant waxes, particularly long-chain $n$-alkanes and fatty acids, are used to reconstruct past vegetation (Xie et al., 2002; Zhang et al., 2006; Zech et al., 2009b, 2010), while stable carbon isotopic $\left(\delta^{13} \mathrm{C}\right)$ and $\mathrm{D} / \mathrm{H}$ (deuterium/hydrogen) analyses of these compounds provide valuable information about changes in paleohydrology and paleoclimate (Liu and Huang, 2005; Zech et al., 2011b, 2013).

The main premise of such reconstructions is the assumption that the biomarkers are deposited synsedimentary with dust and are not subject to postsedimentary overprinting. For long-chain $n$-alkanes and fatty acids, which are thought to be mainly produced above ground as epicuticular leaf waxes, this assumption seems reasonable given their low solubility and hence limited mobility. However, pre-aged organic matter can be transported by wind and redeposited together with dust (Liu et al., 2007; Eglinton et al., 2002). Moreover, Gocke et al. $(2013,2014)$ suggested that significant amounts of long-chain $n$-alkanes and fatty acids are produced within rhizoliths in the vicinity of root systems. Labeling experiments have also suggested potential contributions of root-derived plant-wax biomarkers (Wiesenberg et al., 2010). Furthermore, litter bag studies indicate some 

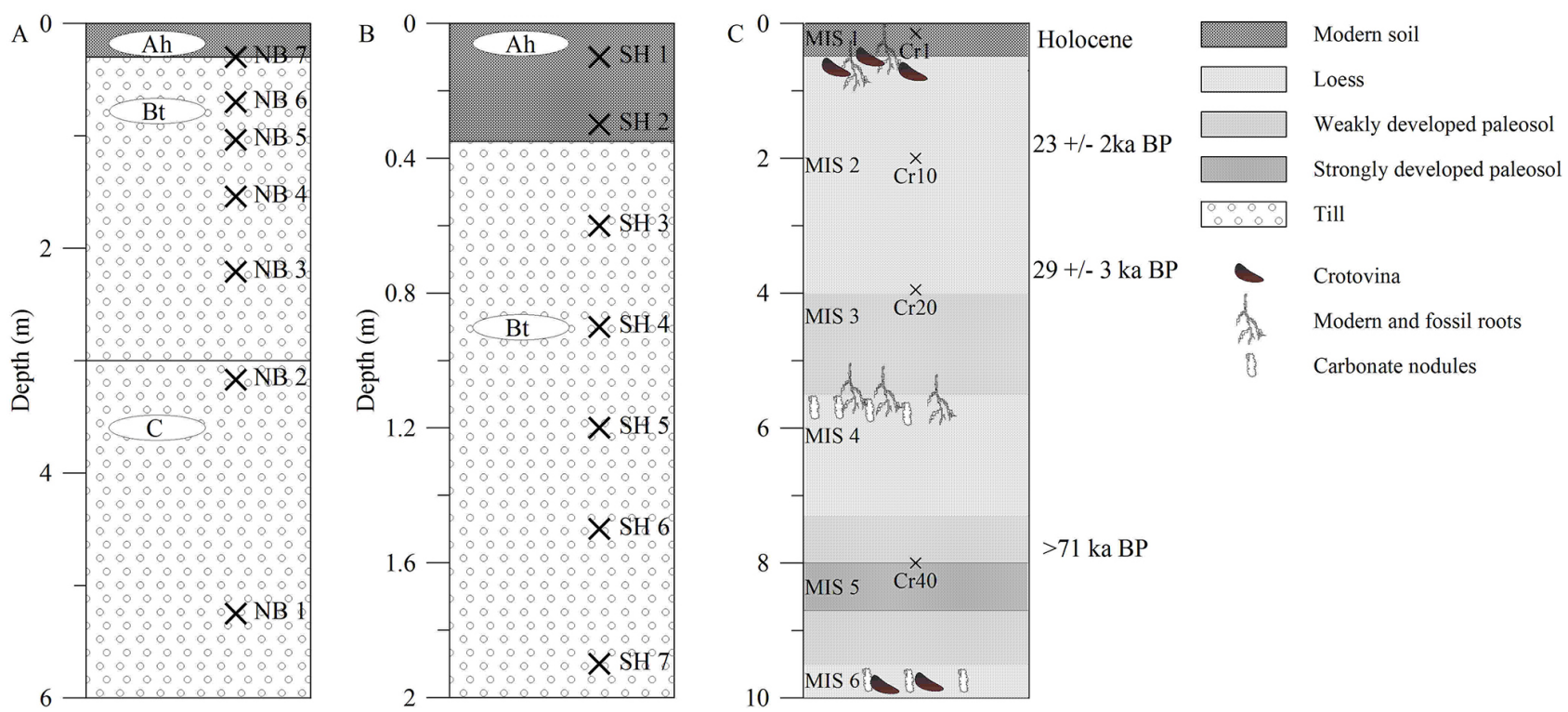

Fig. 1. Sketches of the sediment profiles Niederbuchsiten (A) and Steinhof (B), as well as the LPS Crvenka (C). Samples selected for this study are marked, together with the estimated sediment ages.

microbial production of long-chain $n$-alkanes in the early stages of litter degradation (Nguyen Tu et al., 2011; Zech et al., 2011a). Each of these processes could potentially overprint the original biomarker signal laid down at the time of deposition. The quantification of the above effects and their implications for plant-wax lipid-based proxy reconstructions remains equivocal.

In the present study two different approaches were chosen to evaluate the stratigraphic integrity of leaf-wax biomarkers.

(i) Two sediment profiles through glacial till on the Swiss Plateau were analyzed for their biomarker concentrations. The profiles consisted of a topsoil $\left(A_{\mathrm{h}}\right.$ horizon) as well as the underlying $B$ and $C$ horizons. As glacial sediments are extremely poor in organic material, the presence of large amounts of leaf-wax markers in the subsurface (B and C horizons) is not expected and would indicate postsedimentary contributions from roots or overprint by microorganisms.

(ii) Compound-specific radiocarbon analysis was performed on leaf waxes extracted from selected intervals from a LPS in Serbia, and resulting ages were compared to independent, published ages for this section based on luminescence and stratigraphy, as well as bulk organic carbon ${ }^{14} \mathrm{C}$ ages.

\section{Material and methods}

\subsection{Geographical setting and sampling}

\subsubsection{Sediment profiles in till on the Swiss Plateau}

Two sediment profiles on the Swiss Plateau were sampled in summer 2012: an abandoned quarry near Niederbuchsiten ( $483 \mathrm{~m}$ a.s.l.; $47.286^{\circ} \mathrm{N}, 7.780^{\circ} \mathrm{E}$ ), and a 2 m-deep profile dug near Steinhof (593 ma.s.l.; $\left.47.155^{\circ} \mathrm{N}, 7.682^{\circ} \mathrm{E}\right)$. The site near Niederbuchsiten comprises a luvisol developed in till, which is thought to have been deposited during the penultimate glaciation, i.e., before $130 \mathrm{ka}$ (Bitterli et al., 2011). An $A_{\mathrm{h}}$ horizon at the top $30 \mathrm{~cm}$ of the profile overlies the $B_{\mathrm{t}}$ horizon, which is followed by the $\mathrm{C}$ horizon below $3 \mathrm{~m}$ depth. Seven samples were collected to a depth of $\sim 6 \mathrm{~m}$ (Fig. 1a). The Steinhof site is situated close to the northwestern edge of the last glacial maximum extent of the Valais Glacier, and the till there was likely deposited $\sim 20 \mathrm{ka} \mathrm{BP}$ (before present; Bini et al., 2009; Bitterli et al., 2011; Ivy-Ochs et al., 2004). The top $35 \mathrm{~cm}$ of the Steinhof profile are an $A_{\mathrm{h}}$ horizon, followed by a $B_{\mathrm{t}}$ horizon $(35-200 \mathrm{~cm}$ depth). The decalcification depth was reached in a core at $3.9 \mathrm{~m}$. Seven samples were collected approximately every $30 \mathrm{~cm}$ down to a depth of $2 \mathrm{~m}$ (Fig. 1b).

\subsubsection{The loess-paleosol sequence Crvenka}

The LPS Crvenka is situated in a brickyard on the southwestern edge of the Bačka loess plateau, $150 \mathrm{~km}$ northwest of Belgrade, Serbia ( $108 \mathrm{~m}$ a.s.l.; $45.663^{\circ} \mathrm{N}, 19.480^{\circ} \mathrm{E}$ ). The profile consists of a Holocene-age topsoil that caps about $8 \mathrm{~m}$ 
of loess attributed to marine isotope stage (MIS) 2 and MIS 4 (Fig. 1c). A weakly developed paleosol complex formed during MIS 3 (i.e., between $\sim 57$ and $29 \mathrm{ka}$ ) in a depth of $4-5.5 \mathrm{~m}$. Below the MIS 4 loess, at $\sim 8 \mathrm{~m}$ depth, a welldeveloped $2 \mathrm{~m}$ thick clay-rich paleosol follows, documenting intensive pedogenesis and reduced dust accumulation during MIS 5 ( 130-71 ka). The lowermost part of the section consists of loess deposited during MIS 6. Modern roots are found in the Holocene topsoil and the upper parts of the MIS 2 loess. Fossil roots are evident in the MIS 3 and MIS 5 paleosols and the upper parts of the underlying MIS 4 and MIS 6 loess units. Previous studies in the LPS Crvenka were conducted using a wide range of analytical tools, including magnetic susceptibility, grain size analysis, geochemistry, and biomarkers (Marković et al., 2008; Zech et al., 2009a, 2013). Extensive chronological work has also been conducted using optically stimulated luminescence (OSL) and elevated temperature post-IR infrared-stimulated luminescence (post-IR IRSL) (Stevens et al., 2011).

For this study, four samples from a field campaign in summer 2009 were selected (Fig. 1c): one sample from the Holocene topsoil ( $25 \mathrm{~cm}$ depth, label: $\mathrm{Cr} 1)$, one from the MIS 2 loess ( $2 \mathrm{~m}$ depth, $\mathrm{Cr} 10$ ), one from the uppermost MIS 3 paleosol (4 $\mathrm{m}$ depth, $\mathrm{Cr} 20$ ), and one from the top of the MIS 5 paleosol (8 $\mathrm{m}$ depth, $\mathrm{Cr} 40$ ). The depositional ages of these four samples are estimated based on stratigraphy and luminescence as Holocene (Cr 1), $23 \pm 2 \mathrm{ka}$ (Cr 10), $29 \pm 3 \mathrm{ka}$ (Cr 20), and $>71 \mathrm{ka}(\mathrm{Cr} 40)$. While the age of $\mathrm{Cr} 10$ is well constrained with luminescence (Stevens et al., 2011), the age of $29 \pm 3 \mathrm{ka}$ for $\mathrm{Cr} 20$ is bracketed by luminescence ages of $22 \pm 2 \mathrm{ka}$ and $33 \pm 3 \mathrm{ka}$ above and below our sample, and $29 \mathrm{ka}$ is also the stratigraphic boundary age between MIS 2 and MIS 3 (Lisiecki and Raymo, 2005).

\subsection{Sample preparation and analyses}

The samples from the Swiss sediment profiles were freezedried (Christ ALPHA LDplus), homogenized gently, and sieved to $<2 \mathrm{~mm}$. The loess samples from Crvenka were dried at room temperature and homogenized. Free lipids were obtained from sample aliquots (30-40 g dry weight) with a Dionex ASE 200 accelerated solvent extractor using dichloromethane and methanol (DCM: $\mathrm{MeOH} ; 9: 1)$ at $1500 \mathrm{psi}$ (pounds per square inch) and $100{ }^{\circ} \mathrm{C}$ for three cycles lasting $5 \mathrm{~min}$ each. For the samples assigned for compound-specific radiocarbon dating, this extraction protocol was repeated three times in order to obtain sufficient material. The total lipid extracts were separated over aminopropyl columns. $n$-Alkanes were eluted with hexane, polar lipids were eluted with $\mathrm{DCM}: \mathrm{MeOH}(1: 1)$, and free fatty acids were eluted with diethyl ether: acetic acid (19:1). The fatty acid fraction was methylated at $80^{\circ} \mathrm{C}$ with methanolic $\mathrm{HCl}\left(\mathrm{MeOH} \Delta{ }^{14} \mathrm{C}:-995.6 \%\right.$ ) : yielding the corresponding fatty acid methyl esters (FAMEs). The compounds were recovered by liquid-liquid extraction using hexane and were subsequently cleaned over silica columns. Fatty acid and $n$-alkane concentrations were determined using an Agilent Technologies 7890A gas chromatograph (GC) equipped with a VF1 column $(30 \mathrm{~m}, 0.25 \mathrm{~mm}, 0.25 \mu \mathrm{m})$ and a flame ionization detector (FID). Compounds were quantified using $5 \alpha$-androstane and identified by comparison with external standards.

The $n$-alkanes and FAMEs for compound-specific radiocarbon dating were further purified using $\mathrm{AgNO}_{3}$ and zeolite (Geokleen) pipette columns. The zeolite, which occludes straight-chain ( $n$-alkyl) compounds, was dissolved in HF after drying, and target compounds were then recovered by liquid-liquid extraction with hexane. Specific $n$-alkane and FAME homologues were isolated using a Gerstel preparative fraction collector coupled to an Agilent Technologies 7890A GC system equipped with a VF1 column $(30 \mathrm{~m}, 0.53 \mathrm{~mm}$, $0.5 \mu \mathrm{m})$. The isolated compounds were recovered with DCM, passed through pipette columns $\left(\mathrm{SiO}_{2}\right)$ to remove column bleed, and transferred to quartz tubes. After removal of solvent, a small quantity of $\mathrm{CuO}$ was added before the tubes were evacuated to $10^{-3}$ mbar over a vacuum line and flame sealed. Compounds were combusted at $850^{\circ} \mathrm{C}(6 \mathrm{~h})$ and the resulting $\mathrm{CO}_{2}$ was purified over a $\sim-70^{\circ} \mathrm{C}$ butylacetate water trap on a vacuum line. $\mathrm{CO}_{2}$ was then quantified manometrically and subsequently sealed in Pyrex tubes. Radiocarbon measurements were conducted on a MICADAS (Mini Carbon Dating System) accelerator mass spectrometry (AMS) system (Synal et al., 2007; Wacker et al., 2013) at the Laboratory for Ion Beam Physics (LIP), ETH Zürich.

For total organic carbon (TOC) measurements, the soil samples were first treated with $\mathrm{HCl}\left(1 \mathrm{M}, 60^{\circ} \mathrm{C}, 12 \mathrm{~h}\right)$ in order to remove carbonates, rinsed five times with Milli-Q water and dried $\left(60^{\circ} \mathrm{C}\right)$. Aliquots of around $50 \mu \mathrm{g}$ were weighed into tin capsules for elemental and stable carbon isotopic analysis (FlashEA 1112 elemental analyzer (EA) coupled to a Thermo Scientific Delta V plus isotope ratio mass spectrometer (IRMS)).

For comparison with the compound-specific data, ${ }^{14} \mathrm{C}$ analysis was performed on bulk organic matter from the four Crvenka samples. Samples were first rinsed with 6 molar $\mathrm{HCl}$ at $60^{\circ} \mathrm{C}$ for several hours to ensure complete removal of carbonates before rinsing (Milli-Q water) and drying $\left(60^{\circ} \mathrm{C}\right)$. Aliquots containing $\sim 1 \mathrm{mg}$ of carbon were weighed into tin boats and processed using the automated graphitization equipment (AGE-3) at the ETH LIP (Wacker et al., 2010b) prior to radiocarbon analysis.

\subsection{Data processing}

All compound-specific radiocarbon data were corrected for a vacuum line blank of $0.91 \mu \mathrm{gC}$ with a fraction modern $(\mathrm{Fm})$ of $0.23 \pm 4.5 \%$. This value was determined in 2011 by analyses of 10 combined blanks, and is very similar to the vacuum line blank of Shah and Pearson (2007), who derived a blank value of $1 \pm 0.2 \mu \mathrm{gC}$ with a Fm of 0.2. Note that our blank 

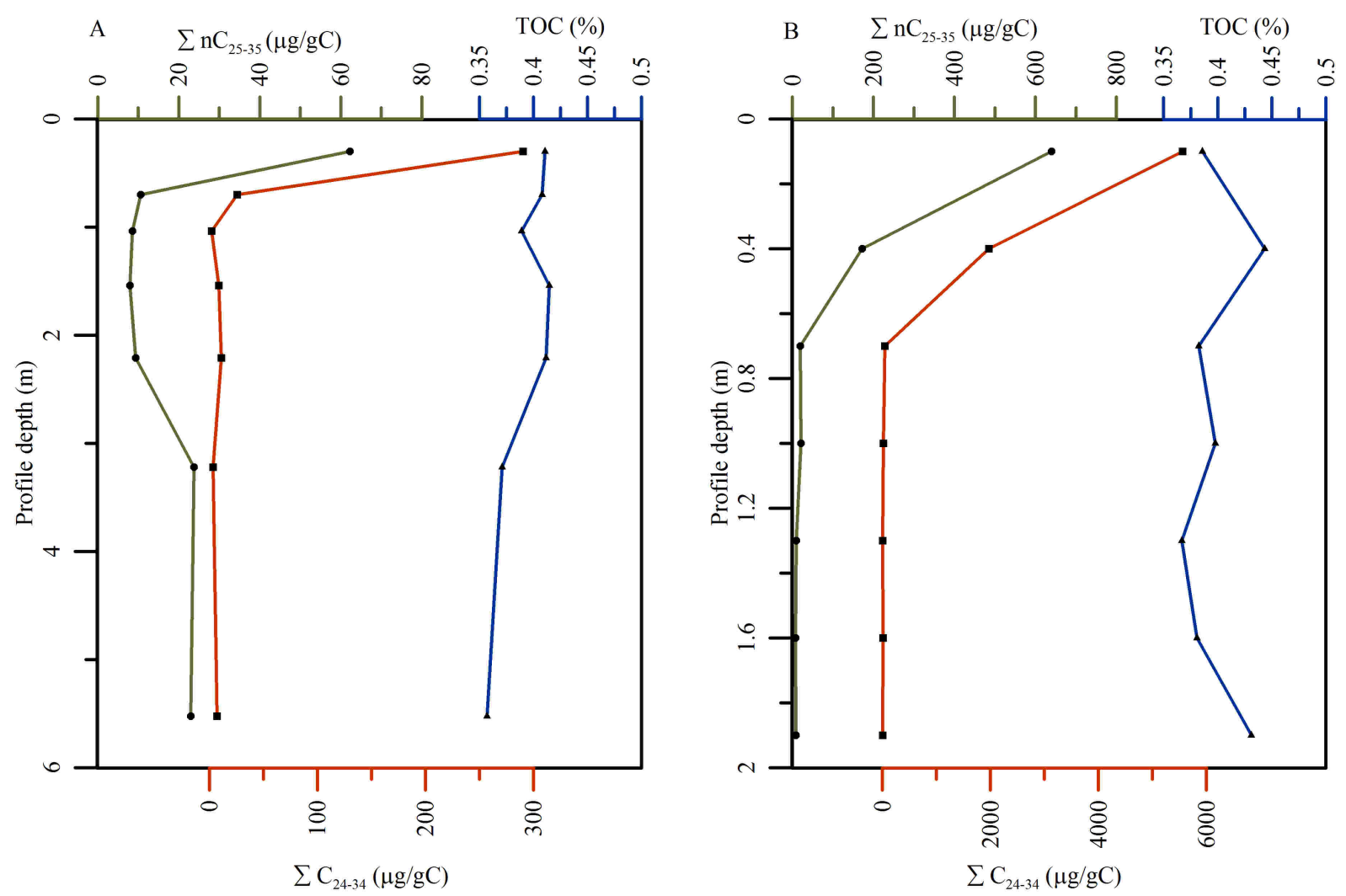

Fig. 2. TOC and leaf-wax concentrations in the sediment profiles Niederbuchsiten (A) and Steinhof (B).

assessment only accounts for contamination during the vacuum line process and is therefore lower than those reported for the entire laboratory process (Shah and Pearson, 2007; Ziolkowski and Druffel, 2009). However, the latter both note that the contamination added during the vacuum line process amounts to the majority of carbon introduced during the laboratory process. Ziolkowski and Druffel (2009) identified also column bleed during the preparative GC step as major source of contamination, but in contrast to the present study these authors did not remove column bleed over silica columns. Thus, the vacuum blank represents a good approximation of the overall contamination introduced during the laboratory process. All FAMEs were additionally corrected for the methyl group added during methylation, yielding the values of the original fatty acids. Bulk measurements were normalized and blank-subtracted against process blanks spiked with IAEA (International Atomic Energy Agency) C3 cellulose and coal respectively. Radiocarbon ages were calculated using the Bats software (Wacker et al., 2010a) and converted to calendar ages using OxCal (Bronk Ramsey, 2009) and the Inc 09 calibration curve (Reimer et al., 2009). All ages in the text are calibrated.

\section{Results}

\subsection{Leaf-wax concentrations in the sediment profiles}

Organic carbon $\left(\mathrm{C}_{\mathrm{org}}\right)$-normalized concentrations of longchain $n$-alkanes $\left(\sum \mathrm{nC}_{25-35}\right)$ and fatty acids $\left(\sum \mathrm{C}_{24-34}\right)$ show a sharp decrease with depth in both sediment profiles in till (Fig. 2). This decrease is particularly pronounced in the Steinhof profile, where the uppermost sample was taken at a depth of only $10 \mathrm{~cm}$, and leaf-wax concentrations are highest ( $\sim 640 \mu \mathrm{g} / \mathrm{gC}$ for $n$-alkanes; $\sim 5600 \mu \mathrm{g} / \mathrm{gC}$ for fatty acids). The uppermost sample for the Niederbuchsiten profile was taken at a depth of $30 \mathrm{~cm}$ and therefore yields already relatively low concentrations. Below a depth of $40 \mathrm{~cm}$ plant-wax biomarker concentrations of only $8-24 \mu \mathrm{g} / \mathrm{gC}(n-$ alkanes) and $2-11 \mu \mathrm{g} / \mathrm{gC}$ (fatty acids) were found in both profiles. The concentrations in most of these subsurface samples are below the limit of quantification (10 times blank) and some are even below the limit of detection (3 times blank). Therefore, the variations seen in Fig. 2 for the subsurface are prone to considerable uncertainty. Furthermore, the low concentrations rendered it impractical to perform radiocarbon dating in both sediment profiles. 
Table 1. Results of compound-specific radiocarbon measurements. All radiocarbon ages were converted to calendar ages using OxCal (Bronk Ramsey 2009) and the Inc 09 calibration curve (Reimer et al., 2009).

\begin{tabular}{|c|c|c|c|c|c|c|c|}
\hline Sample & Compound & $\mu \mathrm{g} \mathrm{C}$ & $\mathrm{Fm}^{14} \mathrm{C}$ & Error & Calendar age & Error & $\delta^{13} \mathrm{C}(\% o)$ \\
\hline \multicolumn{8}{|l|}{$\mathrm{Cr} 1$} \\
\hline $\mathrm{C}_{24}$ & Fatty acid & 25.94 & 0.869 & 0.0129 & 1090 & 200 & -29.1 \\
\hline $\mathrm{C}_{26}$ & Fatty acid & 20.66 & 0.846 & 0.0146 & 1250 & 280 & -29.8 \\
\hline $\mathrm{C}_{28}$ & Fatty acid & 14.60 & 0.801 & 0.0179 & 1730 & 400 & -33.0 \\
\hline $\mathrm{C}_{30}$ & Fatty acid & 21.37 & 0.785 & 0.0134 & 2010 & 290 & -31.4 \\
\hline $\mathrm{C}_{25,27,29,31}$ & Fatty acid & 24.64 & 0.822 & 0.0131 & 1510 & 230 & -29.5 \\
\hline$n \mathrm{C}_{25-27}$ & $n$-alkane & 12.94 & 0.758 & 0.0187 & 2280 & 470 & -31.0 \\
\hline$n \mathrm{C}_{29}$ & $n$-alkane & 18.11 & 0.752 & 0.0150 & 2340 & 390 & -33.9 \\
\hline$n \mathrm{C}_{33-35}$ & $n$-alkane & 9.85 & 0.765 & 0.0230 & 2520 & 230 & -31.7 \\
\hline$n \mathrm{C}_{26,28,30,32,34}$ & $n$-alkane & 10.09 & 0.605 & 0.0190 & 4480 & 620 & -32.1 \\
\hline \multicolumn{8}{|l|}{ Cr10 } \\
\hline$n \mathrm{C}_{29}$ & $n$-alkane & 12.82 & 0.0719 & 0.00517 & 25400 & 1600 & -34.9 \\
\hline$n \mathrm{C}_{31}$ & $n$-alkane & 32.47 & 0.0787 & 0.00304 & 24400 & 880 & -33.1 \\
\hline$n \mathrm{C}_{33-35}$ & $n$-alkane & 29.68 & 0.0963 & 0.00347 & 22500 & 850 & -32.6 \\
\hline$n \mathrm{C}_{26,2}$ & $n$-alkane & 9.56 & 0.0973 & 0.00562 & 22500 & 1100 & -33.3 \\
\hline \multicolumn{8}{|l|}{$\mathrm{Cr} 20$} \\
\hline $\mathrm{C}_{26,28,30,32}$ & Fatty acid & 31.88 & 0.0518 & 0.00285 & 29500 & 880 & -32.9 \\
\hline$n \mathrm{C}_{25-27}$ & $n$-alkane & 10.33 & 0.0837 & 0.00514 & 23800 & 1200 & -33.3 \\
\hline$n \mathrm{C}_{29}$ & $n$-alkane & 22.44 & 0.0540 & 0.00303 & 28300 & 870 & -33.0 \\
\hline$n \mathrm{C}_{31}$ & $n$-alkane & 14.19 & 0.0641 & 0.00388 & 26600 & 1300 & -33.5 \\
\hline$n \mathrm{C}_{26,28,30,32,34}$ & $n$-alkane & 8.84 & 0.053 & 0.00497 & 28400 & 1800 & -33.0 \\
\hline \multicolumn{8}{|l|}{$\mathrm{Cr} 40$} \\
\hline $\mathrm{C}_{26}$ & Fatty acid & 17.87 & 0.0251 & 0.00317 & 34100 & 2300 & -32.9 \\
\hline $\mathrm{C}_{28}$ & Fatty acid & 23.92 & 0.0046 & 0.00242 & 46500 & 3500 & -32.8 \\
\hline $\mathrm{C}_{30}$ & Fatty acid & 33.48 & 0.0090 & 0.00229 & 43200 & 4200 & -33.3 \\
\hline $\mathrm{C}_{32}$ & Fatty acid & 15.32 & 0.0052 & $>50 \%$ & $>45700$ & - & -34.8 \\
\hline $\mathrm{C}_{25,27,29,31,33}$ & Fatty acid & 27.60 & 0.0471 & 0.00235 & 46800 & 3100 & -34.4 \\
\hline$n \mathrm{C}_{25-27}$ & $n$-alkane & 6.35 & 0.0196 & 0.00508 & 37300 & 5000 & -34.4 \\
\hline$n \mathrm{C}_{29}$ & $n$-alkane & 13.30 & 0.0077 & 0.00294 & 45200 & 4800 & -34.8 \\
\hline$n \mathrm{C}_{31}$ & $n$-alkane & 17.99 & 0.0245 & 0.00289 & 34300 & 2200 & -33.7 \\
\hline$n \mathrm{C}_{26,28,30,32,34}$ & $n$-alkane & 7.36 & 0.0074 & 0.00414 & 44600 & 5300 & -34.1 \\
\hline
\end{tabular}

\subsection{Compound-specific radiocarbon analysis of leaf-wax biomarkers in loess}

Concentrations of most $n$-alkane and fatty acid homologues were sufficient for radiocarbon analyses in the four samples from the LPS Crvenka. However, it was necessary to pool some compounds, (e.g., even C-numbered $n$-alkanes and odd $\mathrm{C}$-numbered fatty acids) prior to ${ }^{14} \mathrm{C}$ analysis. Results are summarized in Fig. 3 and documented in Table 1.

The Holocene soil sample $\mathrm{Cr} 1$ exhibits ages between 1 and $2 \mathrm{ka}$ BP. Only the even $n$-alkanes are significantly older ( $\sim 4 \mathrm{ka} \mathrm{BP})$. Radiocarbon ages of plant-wax biomarkers from Cr 10 and $\mathrm{Cr} 20$ are $\sim 23$ and $\sim 29 \mathrm{ka} \mathrm{BP}$, respectively and are in good agreement with the chronostratigraphy. Sample $\mathrm{Cr} 40$ has radiocarbon ages up to $45 \mathrm{ka} \mathrm{BP}$ and can therefore be regarded as almost ${ }^{14} \mathrm{C}$-dead, which is consistent with its stratigraphic position. While the bulk age for $\mathrm{Cr} 20$ is $26 \mathrm{ka}$
$\mathrm{BP}$ and thus also reasonably consistent, the bulk age for $\mathrm{Cr} 10$ is only $18.7 \mathrm{ka} \mathrm{BP}$ and thus significantly too young. Overall, the molecular-level ${ }^{14} \mathrm{C}$ measurements reveal that leaf-wax biomarkers are of similar age as the surrounding sediments, implying that contributions of younger carbon are negligible. Sample Cr 40 , for example, has only $\sim 1 \%$ modern carbon (Table 1).

Several interesting patterns emerge when compoundspecific radiocarbon ages are examined in more detail. For example, $\mathrm{Cr} 1$ is the only sample that shows younger ages for the fatty acids than the alkanes. $\mathrm{Cr} 1$ is also the only sample that has a much older age for the even $n$-alkanes than for the odd ones. And, finally, the $n \mathrm{C}_{25}$ and $n \mathrm{C}_{27}$ alkanes and $\mathrm{C}_{24}$ and $\mathrm{C}_{26}$ fatty acids are systematically younger than the corresponding longer homologues. One exception to this trend is the $n-\mathrm{C}_{33-35}$ alkane sample in $\mathrm{Cr} 10$. However, the 

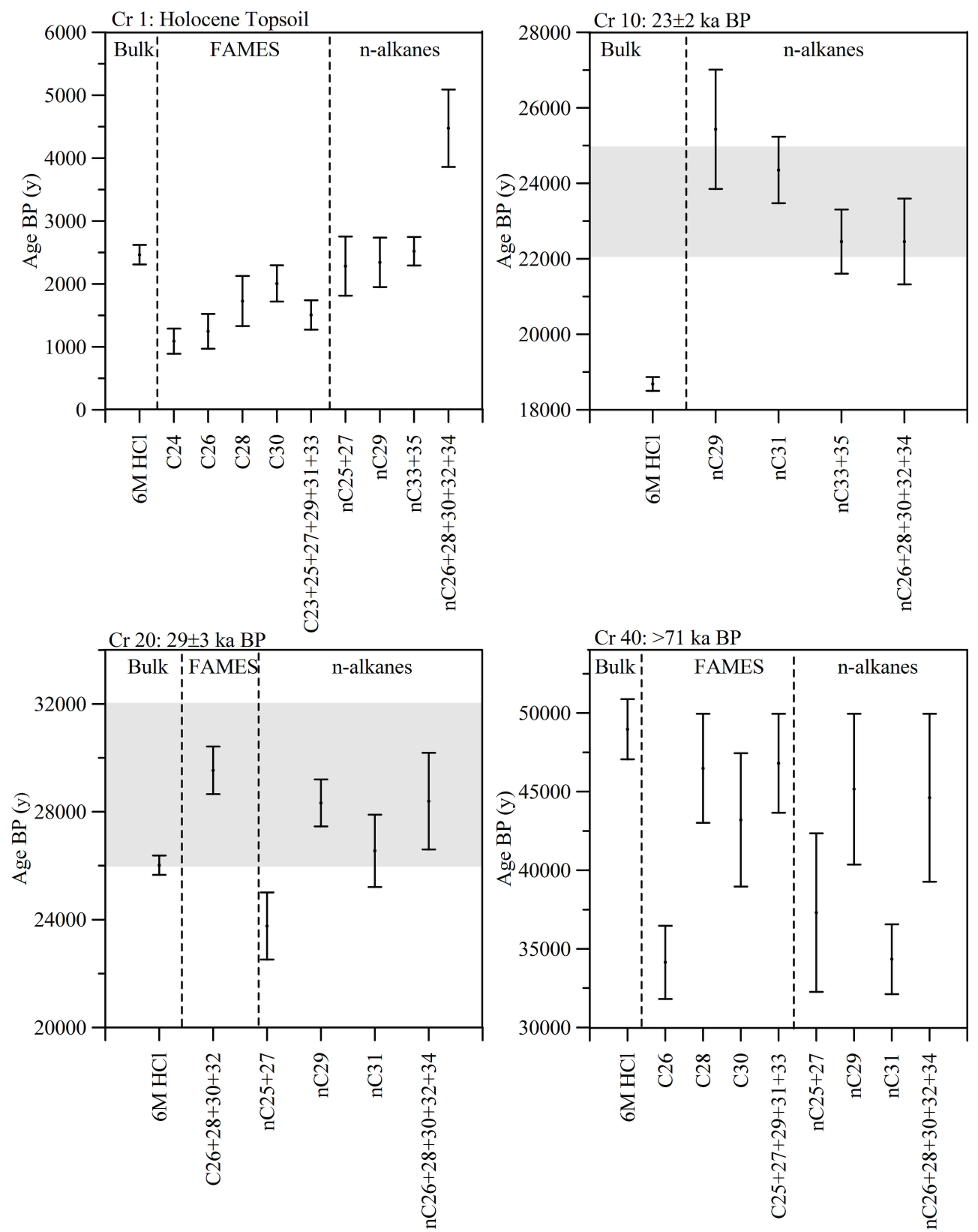

Fig. 3. Compound-specific and bulk radiocarbon ages (calibrated) for the four samples from the LPS Crvenka. The grey bars mark the sediment ages of Cr 10 (23 $\pm 2 \mathrm{ka} \mathrm{BP})$ and $\mathrm{Cr} 20$ (29 $\pm 3 \mathrm{ka} \mathrm{BP})$ based on luminescence and stratigraphy.

observed trends have to be treated with caution, due to the low number of radiocarbon measurements performed.

As a byproduct, the AMS measurement also yielded $\delta^{13} \mathrm{C}$ values of the individual compounds. While these AMS-based $\delta^{13} \mathrm{C}$ measurements carry considerable uncertainty (typically $\pm 3 \%$ ), it is noted that relatively constant values between -29.1 and $-34.8 \%$ were recorded throughout the profile (Table 1).

\section{Discussion}

\subsection{Evaluating the contribution of fossil lipids}

There are several lines of evidence that point to the absence of detectable quantities of leaf-wax lipids derived from fossil sources in the Crvenka samples that might have been introduced during dust transport or by postsedimentary inputs such as fossil fuel.

First, fossil $n$-alkanes are often characterized by low oddover-even carbon number predominance (OEP), with OEP 
values close to one (e.g., Villanueva et al., 1997). OEP values for our samples are much higher $(\sim 10)$, indicative for largely unaltered vascular plant inputs. Likewise, even-overodd predominance of the fatty acids in these samples is approximately four.

Second, a contribution of fossil, reworked lipids would lead to higher ages of the even chain $n$-alkanes compared to the odd homologues (and vice versa for the fatty acids). $n$ Alkanes from fossil (thermogenic) sources have no odd-overeven predominance. Thus, a contribution of fossil $n$-alkanes would lead to overall older ages of even chain $n$-alkanes. With the exception of sample $\mathrm{Cr}$ 1, the samples from the LPS Crvenka do not show such an age pattern. Sample $\mathrm{Cr}$ 1 may contain some fossil alkanes related to recent human activities (Lichtfouse and Eglinton, 1995), but the difference in ${ }^{14} \mathrm{C}$ content between even and odd compounds is small (fraction modern, Fm, 0.6 versus 0.75 , Table 1).

Third, greater ${ }^{14} \mathrm{C}$ ages for $n$-alkanes than for fatty acids would be expected in the case of the presence of reworked fossil material. Fatty acids are more easily degraded during transport and a fossil source would be most apparent in ${ }^{14} \mathrm{C}$ ages of $n$-alkanes (Kusch et al., 2010; Pearson et al., 2001; Uchida et al., 2005). Apart from Cr 1, where a small age difference is observable, there are no significant differences between $n$-alkanes and fatty acids in the Crvenka samples. Consistent with the interpretation above, $\mathrm{Cr} 1$ is the only sample that might contain non-negligible amounts of fossil $n$-alkanes.

Fourth, while variable $\delta^{13} \mathrm{C}$ values among homologues could indicate inputs from more than one source (Liu et al., 2007), $\delta^{13} \mathrm{C}$ values of individual compounds are relatively similar (from $\sim-29$ to $-34 \%$ ), implying a narrow suite of source inputs (see also Table 1).

It should be noted that the above arguments do not rule out synsedimentary contribution of leaf waxes rapidly transported from remote dust source regions, because these signals could have comparable homologue patterns and radiocarbon ages as the leaf-waxes produced locally. Little is known about possible airborne transport of lipid biomarkers, and more research is needed in order to assess this possibility in a more quantitative manner.

\subsection{Evaluating younger, postsedimentary lipid contributions}

The ${ }^{14} \mathrm{C}$ ages of long-chain leaf-wax biomarkers are in good agreement with the sedimentation ages of loess. This suggests that either no or only very small quantities of longchain $n$-alkanes and fatty acids are produced and accumulated at depth. Additional (i.e., postsedimentary) sources of these compounds at depth, for example related to roots or microbial activity, are therefore unlikely to alter the original paleoenvironmental signal.

Although the compounds in each sample have similar ages, a tendency towards older ages can be observed with in- creasing chain length. In particular, the $n \mathrm{C}_{25}$ and $n \mathrm{C}_{27}$ alkanes and $\mathrm{C}_{24}$ and $\mathrm{C}_{26}$ fatty acids are systematically younger than the corresponding longer homologues. This finding is in good agreement with published compound-specific radiocarbon ages of fatty acids in soils (Matsumoto et al., 2007) and fluvially dominated sediments (Drenzek et al., 2007). For soils, the pattern has been explained as a consequence of (i) better solubility of short-chain fatty acids and therefore easier downward leaching into the subsurface and (ii) preferential degradation and production of shorter fatty acids by soil microorganisms. The age pattern of the $n$-alkanes could stem from the same mechanisms, although given the strongly hydrophobic nature of long-chain $n$-alkanes, the influence of microbial activity is likely more relevant than solubility. The production of $n$-alkanes during early litter degradation has been suggested based on litterbag studies (Nguyen Tu et al., 2011; Zech et al., 2011a). The lipid composition of roots shows an enrichment of $n \mathrm{C}_{25}$ and $n \mathrm{C}_{27}$ (Gocke et al., 2014; Jansen et al., 2006; Kuhn et al., 2010). However, the $\mathrm{C}_{29}$ and $\mathrm{C}_{31} n$-alkanes are still prominent in roots and the lipid input by roots would therefore lead to younger ages for all homologues, which is not observed here. Heterotrophic microbial activity could readily explain incorporation of at least some modern carbon in the shorter homologues as consequence of consumption of (young) percolating dissolved organic matter.

The leaf-wax concentrations in the glacial till sections from the Swiss Plateau postsedimentary approach blank values, further arguing against the post sedimentary introduction of plant-wax biomarkers to deeper sediments. In the two studied sections, the concentration of leaf-wax biomarkers drops markedly at depths greater than $\sim 40 \mathrm{~cm}$ below the surface. This depth may vary depending on the parent material, but biomarker data from topsoils along a meridional transect through Europe show that the general trend is similar in a variety of soil types (own unpublished data). The latter study reveals the top $3 \mathrm{~cm}$ contain highest amounts of leaf waxes $\left(8.26_{-5.07}^{+20.22} \mu \mathrm{g} \mathrm{g}^{-1}\right.$ sediment for long-chain $n$-alkanes and $35.94{ }_{-28.09}^{+45.33} \mathrm{\mu g} \mathrm{g}^{-1}$ sediment for fatty acids, $n=23$, Q0.5 $5_{-Q 0.25}^{+Q 0.75}$, and concentrations decrease by a factor of $2-$ 3 by $10 \mathrm{~cm}$ soil depth. For comparison, concentrations in our glacial till (sampled only below $10 \mathrm{~cm}$ ) range from 0.03 to 2.47 and from 0.01 to $21.46 \mu \mathrm{g} \mathrm{g}^{-1}$ sediment, respectively. In contrast to glacial till, accumulatory sediments like loess do not show a large decrease in $n$-alkane concentrations in the subsurface. The $n$-alkane concentrations in the Crvenka section are for instance consistently $>1 \mu \mathrm{g} \mathrm{g}^{-1}$ sediment and are therefore two to three orders of magnitude higher than in glacial till (Zech et al., 2013).

Whereas there seems to be little postsedimentary introduction of $n$-alkanes and fatty acids in the subsurface, bulk organic material is considerably younger than the plant-wax biomarkers in $\mathrm{Cr} 10$. This could be due to the presence of (acid-resistant) organic material related to modern roots, as 
Cr 10 is only $2 \mathrm{~m}$ below the surface. Other studies have explained age differences between bulk lipid fractions and bulk organic matter in soils in a similar way (Bol et al., 1996; Huang et al., 1996).

\section{Conclusions}

Both approaches adopted in this study to test the stratigraphic integrity of leaf-wax biomarkers yielded strong evidence of a co-eval origin with the stratigraphic horizons investigated. On the one hand, concentrations of characteristic plant-wax biomarkers (long-chain $n$-alkanes and fatty acids) were negligible below the topsoil in the two sediment profiles examined in glacial till. On the other hand, compound-specific ${ }^{14} \mathrm{C}$ analysis of the same suites of compounds in the LPS Crvenka yielded ages consistent with independent age control for this sequence based on luminescence and chronostratigraphy. We therefore conclude that subsurface production, input and accumulation of plant-wax lipids related to root, microbial or other postsedimentary processes is negligible at the studied sites. Detailed analysis of the ages of individual $n$-alkyl lipid homologues further indicates that reworking of fossil lipids is also relatively unimportant. The topsoil represents a possible exception and may be related to recent human activity (Lichtfouse and Eglinton, 1995). The slightly younger ages of the $n \mathrm{C}_{25}$ and $n \mathrm{C}_{27}$ alkanes and the $\mathrm{C}_{24}$ and $\mathrm{C}_{26}$ fatty acids than their longer-chain counterparts may reflect the influence of microbial reworking.

Overall, our results confirm the stratigraphic integrity of plant-wax lipids in LPS and underline the potential of plantwax-based proxies for paleoenvironmental reconstructions. Leaf-wax lipids might in fact be particularly useful for dating LPS back to at least $\sim 30 \mathrm{ka}$, because in contrast to bulk soil organic material, they do not appear to be influenced by rootderived carbon inputs.

Acknowledgements. We thank D. Montluçon for help in the laboratory, the SNF for funding (SNF Ambizione PZ00P2_131670), and $\mathrm{V}$. Lanny for providing the unpublished data from the European topsoil transect. Field work in Serbia was kindly supported by S. B. Marković, University of Novi Sad. Two anonymous reviewers and M. Gocke and G. Wiesenberg provided valuable comments and suggestions.

Edited by: N. Ohkouchi

\section{References}

Bini, A., Buoncristiani, J.-F., Couterrand, S., Ellwanger, D., Felber, M., Florineth, D., Graf, H. R., Keller, O., Kelly, M., Schlüchter, C., and Schoeneich, P.: Die Schweiz während des letzteiszeitlichen Maximums (LGM) 1:500 000, Swisstopo, CH3084 Wabern, 2009.
Bitterli, T., Jordi, H., Gerber, M., Gnaegi, C., and Graf, H. R.: Geologischen Atlas der Schweiz 1:25 000. Blatt 1108, Murgenthal, Swisstopo, CH-3084 Wabern, 2011.

Bol, R., Huang, Y., Meridith, J. A., Eglinton, G., Harkness, D. D., and Ineson, P.: The 14C age and residence time of organic matter and its lipid constituents in a stagnohumic gley soil, European Journal of Soil Science, 47, 215-222, 1996.

Bronk Ramsey, C.: Bayesian analysis of radiocarbon dates, Radiocarbon, 51, 337-360, 2009.

Drenzek, N. J., Montluçon, D. B., Yunker, M. B., MacDonald, R. W., and Eglinton, T. I.: Constraints on the Origin of Sedimentary Organic Carbon in the Beaufort Sea from Coupled Molecular ${ }^{13} \mathrm{C}$ and ${ }^{14} \mathrm{C}$ Measurements, Mar. Chem., 103, 146-162, 2007.

Eglinton, T. I. and Eglinton, G.: Molecular proxies for paleoclimatology, Earth Planet. Sci. Lett., 275, 1-16, 2008.

Eglinton, T. I., Eglinton, G., Dupont, L., Montlucon, D., Sholkovitz, E., and Reddy, C. M.: Composition, age, provenance of organic matter in N. W. African dust over the Atlantic Ocean, Geochem., Geophys., Geosyst., 3, 1-27. 2002.

Gocke, M., Kuzyakov, Y., and Wiesenberg, G.: Differentiation of plant derived organic matter in soil, loess and rhizoliths based on n-alkane molecular proxies, Biogeochem., 112, 23-40, doi:10.1007/s10533-10011-19659-y, 2013.

Gocke, M., Peth, S., and Wiesenberg, G. L. B.: Lateral and depth variation of loess organic matter overprint related to rhizoliths - Revealed by lipid molecular proxies and X-ray tomography, Catena, 112, 72-85, 2014.

Huang, Y., Bol, R., Harkness, D. D., Ineson, P., and Eglinton, G.: Post-glacial variations in distributions, ${ }^{13} \mathrm{C}$ and ${ }^{14} \mathrm{C}$ contents of aliphatic hydrocarbons and bulk organic matter in three types of British acid upland soils, Org. Geochem., 24, 273-287, 1996.

Ivy-Ochs, S., Schäfer, J., Kubik, P. W., Synal, H. A., and Schlüchter, C.: Timing of deglaciation on the northern Alpine foreland (Switzerland), Eclogae Geol. Helv., 97, 47-55, 2004.

Jansen, B., Nierop, K. G. J., Hageman, J. A., Cleef, A. M., and Verstraten, J. M.: The straight-chain lipid biomarker composition of plant species responsible for the dominant biomass production along two altitudinal transects in the Ecuadorian Andes, Org. Geochem., 37, 1514-1536, 2006.

Kuhn, T. K., Krull, E. S., Bowater, A., Grice, K., and Gleixner, G.: The occurrence of short chain n-alkanes with an even over odd predominance in higher plants and soils, Org. Geochem., 41, 8895, 2010.

Kusch, S., Rethemeyer, J., Schefuss, E., and Mollenhauer, G.: Controls on the age of vascular plant biomarkers in Black Sea sediments, Geochim. Cosmochim. Acta, 74, 7031-7047, 2010.

Lichtfouse, E. and Eglinton, T. I.: ${ }^{13} \mathrm{C}$ and ${ }^{14} \mathrm{C}$ evidence of pollution of a soil by fossil fuel and reconstruction of the composition of the pollutant, Org. Geochem., 23, 969-973, 1995.

Lisiecki, L. E. and Raymo, M. E.: A Pliocene-Pleistocene stack of 57 globally distributed benthic $\delta^{18} \mathrm{O}$ records, Paleoceanography, 20, PA1003, doi:1010.1029/2004PA001071, 2005.

Liu, W. and Huang, Y.: Compound specific D/H ratios and molecular distributions of higher plant leaf waxes as novel paleoenvironmental indicators in the Chinese Loess Plateau, Org. Geochem., 36, 851-860, 2005.

Liu, W., Yang, H., Ning, Y., and An, Z.: Contribution of inherent organic carbon to the bulk $\delta^{13} \mathrm{C}$ signal in loess deposits from the 
arid western Chinese Loess Plateau, Org. Geochem., 38, 15711579, 2007.

Marković, S. B., Bokhorst, M. P., Vandenberghe, J., McCoy, W. D., Oches, E. A., Hambach, U., Gaudenyi, T., Jovanovi, M., Zöller, L., Stevens, T., and Machalett, B.: Late Pleistocene loesspalaeosol sequences in the Vojvodina region, north Serbia, J. Quat. Sci., 23, 73-84, 2008.

Matsumoto, K., Kawamura, K., Uchida, M., and Shibata, Y.: Radiocarbon content and stable carbon isotopic ratios of individual fatty acids in subsurface soil: implication for selective microbial degradation and modification of soil organic matter, Geochem. J., 41, 483-492, 2007.

Nguyen Tu, T. T., Egasse, C., Zeller, B., Bardoux, G., Biron, P., Ponge, J.-F., David, B., and Derenne, S.: Early degradation of plant alkanes in soils: A litterbag experiment using 13C-labelled leaves, Soil Biol. Biochem., 43, 2222-2228, 2011.

Pearson, A., MeNichol, A. P., Benitez-Nielson, B. C., Hayes, J. M., and Eglinton, T. I.: Origins of lipid biomarkers in Santa Monica Basin surface sediment: A case study using compound-specific analyses, Geochim. Cosmochim. Acta, 65, 3123-3137, 2001.

Reimer, P. J., Baillie, M. G. L., Bard, E., Bayliss, A., Beck, J. W., Blackwell, P. G., Ramsey, C. B., Buck, C. E., Burr, G. S., Edwards, R. L., Friedrich, M., Grootes, P. M., Guilderson, T. P., Hajdas, I., Heaton, T. J., Hogg, A. G., Hughen, K. A., Kaiser, K. F., Kromer, B., McCormac, F. G., Manning, S. W., Reimer, R. W., Richards, D. A., Southon, J. R., Talamo, S., Turney, C. S. M., van der Plicht, J., and Weyhenmeyer, C. E.: IntCal09 and Marine09 Radiocarbon Age Calibration Curves, 0-50 000 Years cal BP, Radiocarbon, 51, 1111-1150, 2009.

Shah, S. R. and Pearson, A.: Ultra-microscale (5-25 $\mu \mathrm{g} \mathrm{C)}$ analysis of individual lipids by ${ }^{14} \mathrm{C}$ AMS: Assessment and correction for sample processing blanks, Radiocarbon, 49, 69-82, 2007.

Stevens, T., Markovic, S. B., Zech, M., Hambach, U., and Sümegi, P.: Dust deposition and climate in the Carpathian basin over an independently dated last glacial-interglacial cycle, Quat. Sci. Rev., 30, 662-681, 2011.

Synal, H. A., Stocker, M., and Suter, M.: MICADAS: a new compact radiocarbon AMS system, Nucl. Instrum. Meth. Phys. Res. B, 259, 7-13, 2007.

Uchida, M., Shibata, Y., Ohkushi, K. I., Yoneda, M., Kawamura, K., and Morita, M.: Age discrepancy between molecular biomarkers and calcareous foraminifera isolated from the same horizons of Northwest Pacific sediments, Chem. Geolol., 218, 73-89, 2005.

Villanueva, J. I., Grimalt, J. O., Cortiljo, E., Vidal, L., and Labeyrie, L.: A biomarker approach to the organic matter deposited in the North Atlantic during the last climatic cycle, Geochim. Cosmochim. Ac., 61, 4633-4646, 1997.

Wacker, L., Christl, M., and Synal, H. A.: Bats: a new tool for AMS data reduction, Nucl. Instrum. Meth. Phys. Res. B, 268, 976-979, 2010a.
Wacker, L., Němec, M., and Bourquin, J.: A revolutionary graphitisation system: Fully automated, compact and simple, Nucl. Instrum. Meth. Phys. Res. B, 268, 931-934, 2010b.

Wacker, L., Fahrni, S. M., Hajdas, I., Molnar, M., Synal, H.-A., Szidat, S., and Zhang, Y. L.: A versatile gas interface for routine radiocarbon analysis with a gas ion source, Nucl. Instrum. Meth. Phys. Res. B, 294, 315-319, 2013.

Wiesenberg, G. L. B., Gocke, M., and Kuzyakov, Y.: Fast incorporation of rootderived lipids and FAs into soil - evidence from a short term multiple ${ }^{14} \mathrm{CO}_{2}$ pulse labelling experiment., Org. Geochem., 41, 1049-1055, 2010.

Xie, S., Wang, Z., Wang, H., Chen, F., and An, C.: The occurrence of a grassy vegetation over the Chinese loess plateau since the last interglacial: the molecular fossil record, Sci. China Ser. D, 45, 53-62, 2002.

Zech, M., Buggle, B., Leiber, K., Markovic, S., Glaser, B., Hambach, U., Huwe, B., Stevens, T., Sümegi, P., Wiesenberg, G., and Zöller, L.: Reconstructing Quaternary vegetation history in the Carpathian Basin, SE Europe, using n-alkane biomarkers as molecular fossils: problems and possible solutions, potential and limitations, Eiszeitalter und Gegenwart, Quat. Sci. J., 58, 148 155, doi:10.3285/eg.58.2.03, 2009a.

Zech, M., Zech, R., Morrás, H., Moretti, L., Glaser, B., and Zech, W.: Late Quaternary environmental changes in Misiones, subtropical NE Argentina, deduced from multi-proxy geochemical analyses in a palaeosol-sediment sequence, Quat. Int., 196, 121136, $2009 \mathrm{~b}$.

Zech, M., Andreev, A., Zech, R., Mueller, S., Hambach, U., Frechen, M., and Zech, W.: Quaternary vegetation changes derived from a loess-like permafrost palaeosol sequence in northeast Siberia using alkane biomarker and pollen analyses, Boreas, 39, 540-550, doi:10.1111/j.1502-3885.2009.00132.x, 2010.

Zech, M., Pedentchouk, N., Buggle, B., Leiber, K., Kalbitz, K., Markovic, S. B., and Glaser, B.: Effect of leaf litter degradation and seasonality on $\mathrm{D} / \mathrm{H}$ isotope ratios of n-alkane biomarkers, Geochim. Cosmochim. Ac., 75, 4917-4928, 2011a.

Zech, R., Huang, Y., Zech, M., Tarozo, R., and Zech, W.: High carbon sequestration in Siberian permafrost loess-paleosols during glacials, Clim. Past, 7, 501-509, 2011b, http://www.clim-past.net/7/501/2011/.

Zech, R., Zech, M., Marković, S., Hambach, U., and Huang, Y.: Humid glacials, arid interglacials? Critical thoughts on pedogenesis and paleoclimate based on multi-proxy analyses of the loess-paleosol sequence Crvenka, Northern Serbia, Palaeogeogr., Palaeoclim., Palaeoecol., 387, 165-175, 2013.

Zhang, Z., Zhao, M., Eglinton, G., Lu, H., and Huang, C.-Y.: Leaf wax lipids as paleovegetational and paleoenvironmental proxies for the Chinese Loess Plateau over the last 170 kyr, Quat. Sci. Rev., 25, 575-594, 2006.

Ziolkowski, L. A. and Druffel, E. R. M.: Quantification of Extraneous Carbon during Compound Specific Radiocarbon Analysis of Black Carbon, Anal. Chem., 81, 10156-10161, 2009. 